\title{
Spherical Tokamak (ST) Transmutation of Nuclear Wastes ${ }^{+}$
}

\author{
Y.-K. M. Peng ${ }^{\text {a }}$, E. T. Cheng ${ }^{\text {b }}$, J. D. Galambos ${ }^{\text {a }}$, R. J. Cerbone ${ }^{\text {b }}$ \\ PED \\ a Oak Ridge National Laboratory, P. O. Box 2009, Oak Ridge, TN 37831-8071 \\ b TSI Research, Inc., 225 Stevens Ave., Suite 203, Solana Beach, CA 92075 \\ FEB 051960
}

\begin{abstract}
The concept for an ST fusion core that drives a He-cooled, actinide-bearing, molten-salt blanket of moderate power density to generate electricity is examined for the first time. The results show that the fusion core is suited for this purpose and require a level of plasma, power density, engineering, and material performances moderate in comparison with what has been considered desirable for fusion-only power plants. The low aspect ratio of ST introduces a relatively thick, diverted scrape-off layer which leads to reduced heat fluxes at the limiter and divertor tiles. The use of a demountable, watercooled, single-turn copper center leg for the toroidal field coils enables simplifications of the fusion core configuration and improves overall practicality for future power applications. These result in much reduced size and cost of the fusion core for the transmutation power plant relative to an optimized fusion-only fusion core. Surrounded by a separate tritium-breeding zone, the molten-salt blanket concept is in principle less complex and costly than the thermal breeding blankets for fusion. These combine to effect major reductions in the cost and weight of the power core equipment for the transmutation power plant. The minimum cost of electricity for such a power plant is thus reduced from the best fusion-only counterpart by more than $30 \%$, based on consistent but approximate modeling. The key issues, development steps, and the potential value inherent in the ST fusion core in addressing the world needs for nuclear waste reduction and energy production are discussed.
\end{abstract}

\section{INTRODUCTION}

Recent design studies for Accelerator-driven Transmutation of nuclear Waste (ATW) [1] introduced molten-salt blanket concepts that in principle can consume actinides and fission products while producing copious thermal power. Only a small amount of energetic neutrons (a few per cent of the thermal energy produced) is needed to drive such blankets. Relative to previous fusion-fission hybrid blanket concepts $[2,3,4]$, this blanket concept relies on intense thermal neutrons to achieve a high blanket energy multiplication $(\leq 100)$ while maintaining a criticality coefficient $\left(k_{\text {eff }}\right)$ as high as 0.97 . Thermal neutron fluxes in the range of $\sim 10^{15} \mathrm{n} \cdot \mathrm{cm}^{-2} \cdot \mathrm{s}^{-1}$ lead to high peak power densities $\left(\sim 1 \mathrm{~kW} \cdot \mathrm{cm}^{-2}\right)$ in the blankets [1]
This type of blanket introduces the possibility of using small D-T-fueled tokamak fusion core to drive a transmutation power plant. Relative to the fusion-fission hybrid concept, the fissile material inventory could be reduced by reducing the blanket/first wall area and increasing the blanket power density while maintaining a significant fusion neutron wall loading. Recent assessments [5] have suggested that a fusion neutron wall loading $W_{\mathrm{L}}$ of the order of $1 \mathrm{MW} \cdot \mathrm{m}^{-2}$ would be appropriate for this application.

Future transmutation power plants can be defined by blanket thermal powers of about $3000 \mathrm{MW}$ and a blanket energy multiplication as high as $30-100[1,6,7]$. This suggests that the following conditions are required of the tokamak fusion core:

1. Fusion power $\geq 30 \mathrm{MW}$,

2. $14-\mathrm{MeV}$ neutron wall loading $\leq 1 \mathrm{MW} \cdot \mathrm{m}^{-2}$,

3. First wall area for blanket $\geq 30 \mathrm{~m}^{2}$, and

4. Device power supply $\leq 250 \mathrm{MW}$.

Recent considerations $[8,9]$ suggested that a small D-T-fueled ST fusion core may well fit these conditions.

This paper presents the initial results of studies on the fusion core based on the ST configuration [10], a transmutation blanket concept and the neutronics analysis for a power core driven by the fusion core, and the systems design analysis of the resulting transmutation power plant. The physics assumptions and basis consistent with today's tokamak and ST data base are presented in Section II. The diverted scrapeoff layer (SOL) configuration that reduces the heat fluxes on divertor and limiter is reviewed in Section III. A fusion core design concept and the parameters are delineated in Section IV. The results of neutronics analysis for a He-cooled, molten-salt transmutation blanket fitted with the ST fusion core are summarized in Section $\mathrm{V}$. The systems code analysis results for such transmutation power plants are presented in Section VI in comparison with ST fusion-only power plants. Key conclusions, important issues, and the potential values inherent in the ST fusion core in addressing the world needs for nuclear waste reduction and energy production are discussed in Section VII.

\section{PHYSICS ASSUMPTIONS AND BASIS}

'Research sponsored by the TSI Research under the Small Business Innovative Research Program and the Office of Fusion Energy, U.S. Department of Energy, under contract DE-AC05-84OR21400 with Lockheed Martin Energy Systems, Inc. 
Recent progress in ST physics data base has been encouraging [11] and introduced some confidence in assuming tokamaklike behaviors for future ST plasmas. The plasma physics assumptions and operating constraints appropriate for the ST fusion core in this study are summarized in Table $I$ in comparison with the pulsed plasma conditions obtained so far in JET [12,13] and DIII-D [14,15]. A lower bound of $0.6 \mathrm{~m}$ in plasma minor radius $(a)$ is required, as in the case of DIII$D$ [14], to ensure that the plasma temperature in the core can exceed $\sim 10 \mathrm{keV}$, the minimum needed for strong D-T burn. Plasma elongations of $\kappa \leq 2.3$ are lower than the highest observed so far in START [16]. The subscript "95" refers to the surface containing $95 \%$ poloidal flux in the plasma. The normalized plasma beta limit (Troyon beta factor $g_{\mathrm{T}} \equiv \beta_{\mathrm{N}} \equiv$ $\left.\beta a B_{\mathfrak{n}} / I_{\mathrm{p}} \leq 0.03 \mathrm{~m} \cdot \mathrm{T} \cdot \mathrm{MA}^{-1}\right)$ is within those recently observed in DIII-D [15], but is below the latest stability computations [17]. Here the average $\beta$ is defined relative to the average magnetic field in the plasma [18]; $B_{00}$ is the externally applied toroidal field at the plasma major radius $R_{0}$; and $I_{\mathrm{p}}$ is the plasma current. A confinement improvement factor $H_{89-\mathrm{p}} \leq 2$ (relative to the ITER-89P scaling [19]) assumed for the fusion core, below the best values obtained in present experiments for H-mode plasmas [15]. Higher safety factors $\left(q_{95} \geq 6\right)$ are assumed as indicated in recent START measurements [16]. The ST fusion core is expected to perform similarly to DIII-D and JET in these plasma properties.

In contrast with these experiments, non-inductive current drive will be required for the ST fusion core to maintain steady-state plasma and neutron production. The limited

Table I

ST fusion core plasma assumptions for waste transmutation in comparison with JET and DIII-D

\begin{tabular}{lcc}
\hline Plasma Parameters & ST & JET, DIII-D \\
\hline Minor radius, $a(\mathrm{~m})$ & $\geq 0.6$ & $0.6-1.2$ \\
Edge elongation, $\mathrm{K}$ & $\leq 2.3$ & $\leq 2.0$ \\
Edge triangularity, $\delta$ & $\leq 0.5$ & $0.4-0.7$ \\
Safety factor, $q_{95}$ & $\geq 6$ & $\geq 2.5$ \\
Normalized $\beta_{\mathrm{N}}\left(\mathrm{m} \cdot \mathrm{T} \cdot \mathrm{MA}^{-1}\right)$ & $\leq 0.03$ & $0.03-0.05$ \\
$H_{\mathrm{f}}(\mathrm{ITER}-89 \mathrm{P}$ scaling $[19])$ & $\leq 2$ & $\leq 4$ \\
$\gamma_{\mathrm{CD}}\left(10^{20} \cdot \mathrm{A} \cdot \mathrm{W}^{-1} \cdot \mathrm{m}^{-2}\right)$ & $\leq 0.3$ & $\leq 0.3$ \\
Surface heat flux $\left(\mathrm{MW} \cdot \mathrm{m}^{-2}\right)$ & $\leq 0.5$ & $\leq 0.1$ \\
Fraction of radiated power & $\leq 0.5$ & $0.2-0.5$ \\
Divertor configuration & natural & $\times-$ point \\
SOL thickness, $\Delta_{\text {SOL }}(\mathrm{m})$ & $\geq 0.1$ & $\geq 0.01$ \\
Edge ion dens., $n_{\mathrm{i}}\left(10^{20} \mathrm{~m}^{-3}\right)$ & 0.3 & $\leq 0.5$ \\
Edge ion temp., $T_{\mathrm{i}}(\mathrm{keV})$ & 0.5 & $\leq 1.0$ \\
\hline
\end{tabular}

space inboard of the plasma torus does not permit a solenoid for inducing temporary plasma current. The magnitude of the non-inductive current drive efficiency required for the ST plasma is assumed to be similar to those already achieved using neutral beam injection [20] or projected for $\mathrm{rf}$ injection [21] $\left(I_{\mathrm{CD}} / P_{\mathrm{CD}} \equiv \gamma_{\mathrm{CD}} / R_{0}\left\langle n_{\mathrm{e}}\right\rangle, \gamma_{\mathrm{CD}} \leq 0.3 \times 10^{20} \mathrm{~A} \cdot \mathrm{W}^{-1} \cdot \mathrm{m}^{-2}\right)$. Here $I_{\mathrm{CD}}$ and $P_{\mathrm{CD}}$ are the driven current and current drive power, respectively; and $\left\langle n_{\mathrm{e}}\right\rangle$ is the average plasma electron density. Deuterium and Tritium neutral beams at $0.5-1.0 \mathrm{MV}$ in energy [22] is assumed. Non-inductive initiation and ramp-up of the plasma current will also be required. There is a significant but preliminary data base in standard tokamaks $[23,24]$ and the ST $[25]$ for such operations.

The heat flux averaged over the ST plasma surface can be much higher than the maximum encountered so far in DIII-D and JET. For plasmas with diversion of heat flux away from edge, the loading on the first wall is expected to be primarily due to radiation (Bremmstrahlung, impurity line, and synchrotron). Assuming that this can be as high as $50 \%$ of the total plasma heating power, the maximum average radiation heat loading on the first wall therefore can be $\sim 0.5 \mathrm{MW} \cdot \mathrm{m}^{-2}$ if $W_{\mathrm{L}} \sim 1 \mathrm{MW} \cdot \mathrm{m}^{-2}$, for driven plasmas $(Q \sim 1)$. The ST assumptions in these areas are expected to differ significantly from the operating conditions of DIII-D and JET.

\section{NATURALLY DIVERTED SOL}

The ST plasma differs from the standard tokamaks in this area because the outboard SOL is diverted naturally without divertor coils. Recent measurements [26] of the SOL plasma in START have indicated this possibility. Fig. 1 shows the equilibrium flux surfaces for such a configuration for $A$ ( $\equiv$ $R_{0}(a)=1.2$ utilizing only two pairs of outboard poloidal field coils for controlling the plasma position and elongation. The

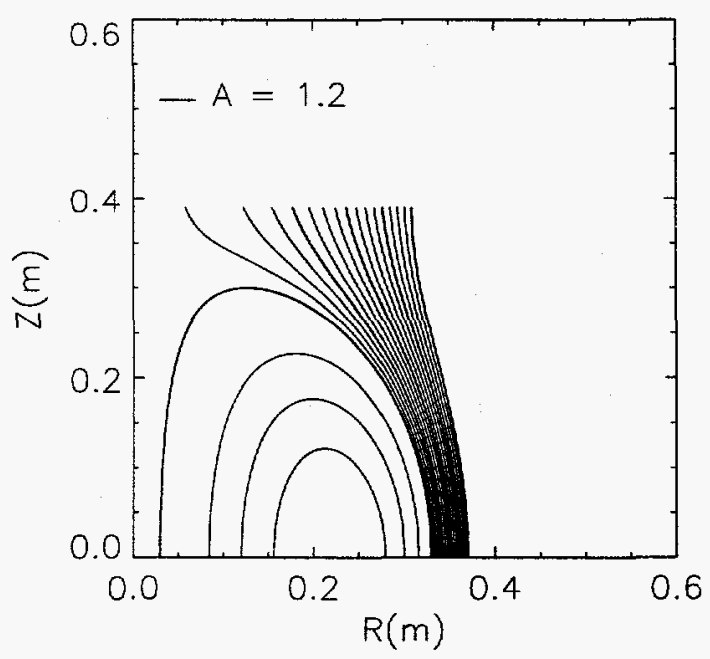

Fig. 1. ST plasma with naturally diverted SOL without using poloidal divertor coils to form $\times$-points at plasma edge. 
total ampere-turns in these poloidal field coils are calculated to be about $80 \%$ of the plasma current in such cases.

This phenomenon can be understood to be in part due to the nearby naturally occurring separatrices on the vertical axis of the torus, a situation observed in low-A tori [27]. If $\Delta_{\text {SOL }}$ far exceeds the flux tube thickness between the plasma edge and the natural separatrix, a significant fraction of the plasma exhaust power becomes "diverted" away from the inboard limiter into the highly expanded flux tubes above and below the plasma (Fig. 1). Comparisons were made recently [28] of $\Delta_{\text {sol }}$ for varying connection lengths $L_{\text {conn }}$ in START. The results showed roughly that $\Delta_{\mathrm{SOL}} \propto L_{\mathrm{conn}}{ }^{2}$, as required by marginal stability condition for pressure-driven MHD modes in the outboard SOL [27]. The minimum $\Delta_{\mathrm{SOL}}$ that satisfies this condition can increase by an order of magnitude as $\mathrm{A}$ is decreased from the standard values to 1.2 (Table I).

The heat flux reaching the inboard is also influenced by the poloidal distribution of heat and particle diffusivities at the plasma edge and the inboard-to-outboard ratio $\left(f_{\text {area }}\right)$ of the plasma surface area. The inboard-to-outboard ratio of the edge exhaust power $\left(f_{\text {power }}\right)$ were measured in DIII-D [29] and START [26] and are plotted in Fig. 2 together with $f_{\text {area }}$ modeled for typical plasma cross sections in these experiments. The results indicate an approximate relationship: $f_{\text {power }} \approx 0.5 f_{\text {area }}$, which is consistent with larger plasma diffusivities in the bad-curvature region (outboard) than in the good-curvature region (inboard).

This relationship suggests that it is reasonable to assume tentatively that $f_{\text {power }} \sim 0.05-0.1$ for ST's with $A=1.2-1.3$ and

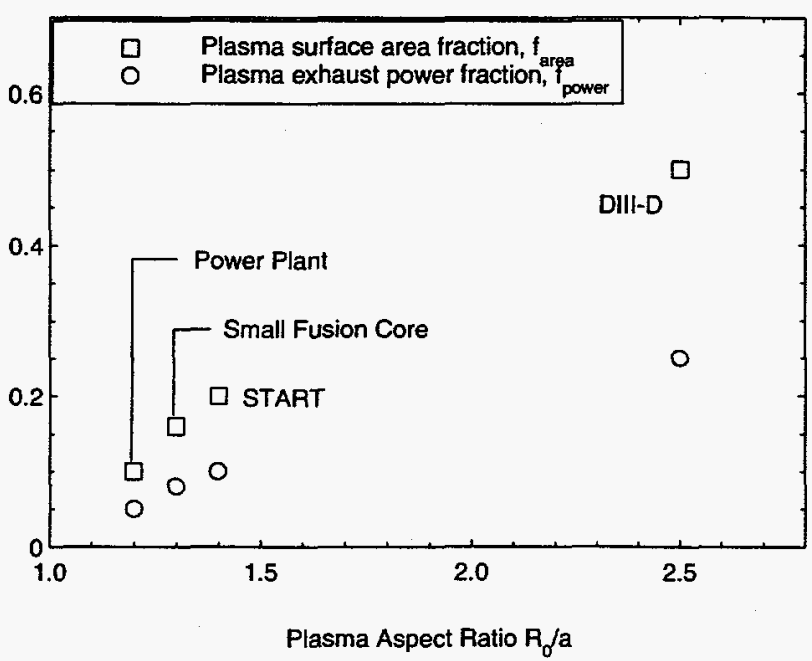

Fig. 2. Measured values of $f_{\text {power }}$ for DIII-D [29] and START [26]; calculated values of $\mathrm{f}_{\text {area }}$ for DIII-D $(A=2.5, \kappa=2.0)$, START $(A=$ 1.4, $\mathrm{K}=1.6$ ), and ST's with $A=1.3, \mathrm{~K}=2.3$, and $A=1.2, \mathrm{~K}=2.3$; and suggested values of $f_{\text {power }}$ for the small ST fusion core and power plant. Here the triangularity of the plasma edge cross section is assumed to be 0.5 . $k=2.3$. The calculated values for $f_{\text {area }}$ for this configuration are also plotted in Fig. 2. The average heat flux at the inboard plasma edge is approximately given by, in the absence of radiative loss,

$$
\Phi_{\text {in }} \approx 0.25\left(f_{\text {power }} / f_{\text {area }}\right)\left[\left(1+f_{\text {area }}\right) /\left(1+f_{\text {power }}\right)\right][1+(5 / Q)] W_{\mathrm{L}}
$$

This leads to a modest $\Phi_{\text {in }} \approx 0.23 \mathrm{MW} / \mathrm{m}^{2}$ for a driven fusion core with $A=1.2, W_{\mathrm{L}}=0.5 \mathrm{MW} / \mathrm{m}^{2}, Q=2$, and $f_{\text {power }}=0.05$.

The outboard "divertor" heat flux can be estimated by assuming plate surfaces inclined by $45^{\circ}$ from vertical for $R$ up to $R_{0}$. The average heat flux on these "divertor" plates is approximately given by,

$$
\Phi_{\text {out }} \approx 0.35 \pi \sqrt{ } \kappa\left[1 /\left(1+f_{\text {power }}\right)\right][1+(5 / Q)] W_{\mathrm{L}} .
$$

A more significant but still feasible heat flux of $\Phi_{\text {out }}=2.8$ $\mathrm{MW} / \mathrm{m}^{2}$ is obtained for the same fusion core. It can therefore be expected that the diverted SOL configuration of the ST fusion core leads to practical heat fluxes on the inboard limiter and the outboard "divertors."

\section{FUSION CORE CONCEPT AND PARAMETERS}

The ST fusion core must be configured for full remote access for the critical components. The critical components include the "divertors," the first wall tiles, the transmutation blanket system, and the normal conducting center leg of the toroidal field coils (TFC). The features that can influence the ST fusion core parameters in this fashion are summarized in Table II and depicted in Fig. 3.

Relatively thick outboard shielding is needed to minimize reactor hall activation and ensure personnel safety and access for hands-on activities. The jointed demountable TFC [30]

Table II

Key configuration and features of the ST fusion core for waste transmutation

\begin{tabular}{lc}
\hline Inboard protection tile thickness $(\mathrm{cm})$ & 1 \\
\hline Outboard shield/blanket thickness $(\mathrm{cm})$ & 140 \\
Vacuum seal welds versus shields & external \\
Number of outboard TFC legs & 8 \\
Single-turn jointed TFC center leg & yes \\
Avg. center leg current dens. $\left(\mathrm{kA} \cdot \mathrm{cm}^{-2}\right)$ & $\leq 2.0^{*}$ \\
Avg. outer leg current dens. (kA.cm & $\leq 1.0$ \\
TFC load path through radiation shield & yes \\
S/C poloidal field coil (PFC) location & internal \\
\hline
\end{tabular}

*averaged over the entire center leg, which is hour-glass shaped at the midsection (see Fig. 3). 


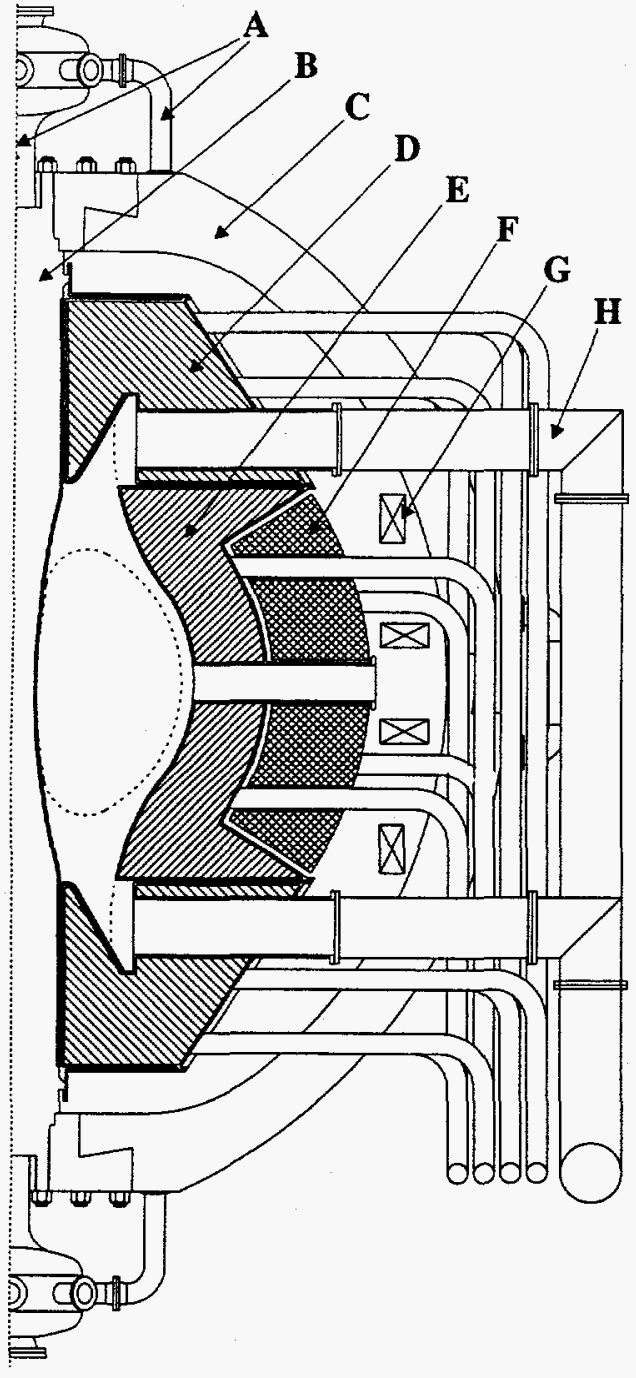

Fig. 3. Elevation view depicting the design features for a waste transmutation power plant driven by an ST fusion core: A - TFC cooling, B - TFC center leg, C - TFC outer legs, D - divertor with shielding, E - blanket and vacuum boundary, F - blanket and shielding, $\mathrm{G}-\mathrm{S} / \mathrm{C}$ poloidal field coils, $\mathrm{H}$ - vacuum pumping.

will permit replacement if necessary of the in-bore PFC, the shield structure, the "divertors," the blanket modules, and the first wall. The jointed, single-turn center leg of the TFC permits remote replacement and removes the need for inboard insulator and significant shielding. The copper center leg and the divertors nevertheless must be replaced on a regular basis, with frequencies determined by their damage life times [31]. The overall average current density for the inner and outer legs of the TFC are limited to $2.0 \mathrm{kA} \cdot \mathrm{m}^{-2}$ and $1.0 \mathrm{kA} \cdot \mathrm{m}^{-2}$, respectively, limiting temperature rises to $150{ }^{\circ} \mathrm{C}$ in the pressurized coolant water [32]. To ensure adequate rigidity of the joints to the TFC center leg, the shields can be configured to carry the bulk of the out-of-plane TFC loads.

The foregoing physics and engineering assumptions for the ST fusion core define the constraints within which desirable design parameters can be estimated. We use the SuperCode [33], modified to account for the low $A$ and the use of steadystate normal conducting TFC [32]. The code permits the determination of design parameters that produce the optimum value for a figure of merit, such as the fusion core equipment cost or the cost of electricity (COE).

The parameters for an ST fusion core providing an outboard neutron wall loading of $\approx 0.6 \mathrm{MW} \cdot \mathrm{m}^{-2}$ are summarized in Table III. This example is suitable for a transmutation power plant utilizing a He-cooled molten-salt blanket to produce $1000 \mathrm{MW}$ in net electricity. The fusion core power consumption includes the TFC supply, the plasma drive power (at $50 \%$ efficiency), plus a $10 \%$ fraction for other support systems. This example indicates for the ST fusion core relatively moderate requirements in plasma performance, size, heat flux, field strength, drive power, and fusion power.

\section{He-COOLED TRANSMUTATION BLANKET}

The preceding ST fusion core can be fitted to a He-cooled transmutation blanket of relatively moderate power densities. This type of blanket has an important advantage in keeping

Table III

Key parameters of an ST fusion core driving a He-cooled moltensalt transmutation blanket in a power plant

\begin{tabular}{lc}
\hline Outboard average $W_{\mathrm{L}}\left(\mathrm{MW} \cdot \mathrm{m}^{-2}\right)$ & 0.6 \\
\hline Fusion power, $P_{\text {fusion }}(\mathrm{MW})$ & 67 \\
Major radius, $R_{0}(\mathrm{~m})$ & 1.42 \\
Minor radius, $a(\mathrm{~m})$ & 1.20 \\
Plasma current, $I_{\mathrm{p}}(\mathrm{MA})$ & 19 \\
External toroidal field, $B_{\mathrm{t}}(\mathrm{T})$ & 1.5 \\
Plasma edge $q$ & 12 \\
Normalized $\beta_{\mathrm{N}}\left(\mathrm{m} \cdot \mathrm{T} \cdot \mathrm{MA} \mathrm{A}^{-1}\right)$ & 0.021 \\
Average density, $\left\langle n_{\mathrm{e}}\right\rangle\left(10^{20} \mathrm{~m}^{-3}\right)$ & 0.64 \\
Average temperature, $\langle T\rangle_{\mathrm{n}}(\mathrm{keV})$ & 15.0 \\
Bootstrap current fraction & 0.3 \\
Drive power, $P_{\text {drive }}(\mathrm{MW})$ & 42 \\
Elec. power consumed $(\mathrm{MW})$ & 240 \\
Plasma volume $\left(\mathrm{m}^{3}\right)$ & 81 \\
Plasma surface area $\left(\mathrm{m}^{2}\right)$ & 99 \\
Average plasma edge heat flux $\left(\mathrm{MW} \cdot \mathrm{m}^{-2}\right)$ & 0.6 \\
Average inboard heat flux $\left(\mathrm{MW} \cdot \mathrm{m}^{-2}\right)$ & 0.3 \\
Outboard first wall area $\left(\mathrm{m}^{2}\right)$ & 90 \\
\hline
\end{tabular}


the molten-salt and transuranic inventories apart from the heat transport and exchange systems. He-cooled tritium breeding blankets of low power density are assumed to surround the transmutation blankets. A series of TWODANT [34] 2-D calculations were made to find the optimum neutronics design parameters for maximum consumption of plutonium and neptunium. Fig. 4 shows the R-Z model used.

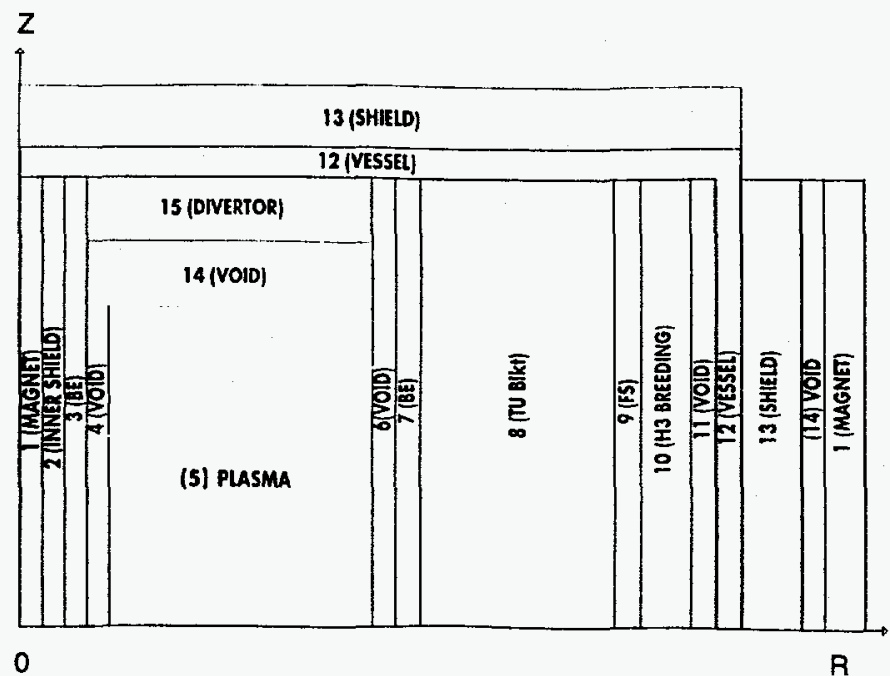

Fig. 4. Schematic two-dimensional neutronics model for the core of an ST transmutation power plant.

Our results are summarized in Table IV, which describes the materials used in the major power core components, and Table V, which describes the assumed blanket composition. The principal blanket design and performance parameters are provided in Table VI. Molten salt, as a carrier transuranic isotopes, is limited to 0.214 in a/o solubility for plutonium. A relatively thick blanket of $1.0 \mathrm{~m}$ is therefore needed to ensure a reasonable $k_{\text {eff }}$, nominally between 0.90 and 0.95 .

The blanket energy multiplication in this case is calculated to be about 33; the tritium breeding ratio is calculated to be 0.95 relative to the incident fusion neutrons. The peak blanket power density is estimated to be less than $100 \mathrm{~W} \cdot \mathrm{cm}^{-3}$. This

Table IV

Material Composition for the Principal Power Core Components

\begin{tabular}{ll}
\hline Region & Material \\
\hline TFC center leg & $70 \%$ Copper, 30\% Water \\
Inboard and outboard walls & $90 \%$ Ferritic Steel (FS), 10\% He \\
Tritium Breeding Blankets & $90 \%$ LiAlO $_{2}, 5 \% \mathrm{FS}, 5 \% \mathrm{He}$ \\
Divertor & $90 \% \mathrm{FS}, 10 \% \mathrm{He}$ \\
Vessel/Shield & $90 \% \mathrm{FS}, 10 \% \mathrm{He}$ \\
\hline
\end{tabular}

Table V

Transuranic Blanket Composition

\begin{tabular}{lll}
\hline Material & Composition & Volume Fraction \\
\hline Molten Salt & $\mathrm{LiF}(66 \%) \mathrm{BeF}_{2}(34 \%)$ & 0.90 \\
Actinides & LWR Discharge & $0.214 \mathrm{a} / \mathrm{o}$ in Molten Salt \\
Structure & Ferritic Steel, He & 0.10 \\
\hline
\end{tabular}

example shows that a power plant, using ST driven Hecooled, molten-salt transmutation blanket is a feasible approach for electrical power production.

\section{ECONOMIC POTENTIAI}

The economic potential for such a power plant is estimated using the modified SuperCode and compared with that for an ST fusion-only power plant. In order to compare with power plants for the standard tokamak based on the advanced physics regime [35], an ST fusion power plant using similar physics assumptions [27] is used. As previously, the cases shown are optimized for minimum COE under a consistent set of physics and engineering design constraints. For the transmutation reactor, the blanket assembly is assumed to surround the plasma and the "natural divertors" in total height (Fig. 3). The blanket power density is limited to an average of $51 \mathrm{~W} \cdot \mathrm{cm}^{-3}$ in sizing thickness and volume. The blanket power generation and removal efficiencies are scaled from several cases used in the TWODANT neutronics calculations.

Table VII summarizes the results of this initial study and indicates the following for the transmutation power plant:

1. More than $30 \%$ reduction in minimum COE is obtained, relative to that for fusion-only power plant.

Table VI

He-Cooled Transuranic Blanket Performance Parameters

\begin{tabular}{lc}
\hline Solubility (a/o) & 0.214 \\
\hline Inboard / outboard $W_{\mathrm{L}}\left(\mathrm{MW} \cdot \mathrm{m}^{-2}\right)$ & $0.34 / 0.48$ \\
Criticality coefficient $\mathrm{k}_{\mathrm{eff}}$ & 0.91 \\
Blanket energy multiplication & 33 \\
Blanket thermal power $(\mathrm{MWt})$ & 2660 \\
Tritium breeding ratio & 0.95 \\
Blanket thickness $(\mathrm{cm})$ & 100 \\
Blanket volume (m $\left.{ }^{3}\right)$ & 170 \\
Inventory: $(\mathrm{MT})$ & \\
$\quad$ Molten salt & 313 \\
$\quad$ Transuranics & 9 \\
\hline
\end{tabular}


Table VII

Parameters for ST Fusion and Transmutation Power Plants of Minimum COE and Producing $1000 \mathrm{MWe}$

\begin{tabular}{|c|c|c|}
\hline & D-T Fusion & Transmutation \\
\hline Energy confinement factor $H_{89-\mathrm{P}}$ & 2.4 & 2.0 \\
\hline Normalized $\beta_{N}\left(m \cdot T \cdot M A^{-1}\right)$ & 0.035 & 0.021 \\
\hline Edge safety factor $q$ & 23 & 12 \\
\hline Fusion core size $R_{0}+a(\mathrm{~m})$ & 5.4 & 2.6 \\
\hline Applied toroidal field $B_{t 0}(\mathrm{~T})$ & 2.3 & 1.5 \\
\hline Plasma current $I_{\mathrm{D}}(\mathrm{MA})$ & 43 & 19 \\
\hline$T_{\mathrm{i}}(0) n_{\mathrm{DT}}(0) \tau_{\mathrm{E}}\left(\mathrm{keV} \cdot 10^{20} \mathrm{~m}^{-3} \cdot \mathrm{s}\right)$ & 56 & 9 \\
\hline Pressure-driven current fraction & 0.95 & 0.3 \\
\hline Plasma drive power (MW) & 55 & 42 \\
\hline Fusion power (MW) & 2810 & 67 \\
\hline Inboard $\Phi_{\text {in }}\left(\mathbf{M W} \cdot \mathrm{m}^{-2}\right)$ & 0.86 & 0.31 \\
\hline "Divertor" $\Phi_{\text {out }}\left(\mathrm{MW} \cdot \mathrm{m}^{-2}\right)$ & 10.5 & 3.8 \\
\hline Blanket thermal power (MW) & 3290 & 3380 \\
\hline Neutron wall load $W_{\mathrm{L}}\left(\mathrm{MW} \cdot \mathrm{m}^{-2}\right)$ & 6.0 & 0.6 \\
\hline Power core weight (ktonne) & 7.6 & 1.3 \\
\hline Total capital cost (1993 \$B) & $\underline{3.64}$ & $\underline{2.60}$ \\
\hline Power core equip. cost fraction & 0.49 & 0.36 \\
\hline Total $\mathrm{COE}\left(\alpha \cdot \mathrm{kW}^{-1} \cdot \mathrm{hr}^{-1}\right)$ & $\underline{8.47}$ & $\underline{5.73}$ \\
\hline Capital investment & 6.18 & 4.40 \\
\hline Operation, Maintenance, fuel ${ }^{a}$ & 2.29 & 1.33 \\
\hline
\end{tabular}

${ }^{a}$ fusion fuel assumed to cover all components requiring scheduled

replacement: blanket, first wall, divertor, tritium, and $\mathrm{Cu}$ center leg.

2. This results primarily from reduction in capital cost, which in turn results from reduction in the power core equipment cost (by a factor of two).

3. This last reduction is derivable from large reductions in size and weight for the fusion core and the blankets.

4. $W_{\mathrm{L}}$ and the damage rate for the TFC center leg are reduced by an order-of-magnitude.

5. Relatively moderate physics performance and plasma parameters are allowed for the fusion core.

6. The balance of plant cost is lowered by about $15 \%$.

7. These cases have similar fractions of recirculating power.

Relative to the lowest COE estimates [27] for power plants using the standard tokamak, the COE ratios for the ST fusion and transmutation power plants are 1: 0.78: 0.53 , respectively. ST transmutation of nuclear wastes therefore possesses high economic potential. Such a power plant is estimated to adequately service the actinide wastes produced by generating 3 to $5 \mathrm{GWe}$ power via pressurized-water reactors (PWR).

\section{CONCLUSION AND DISCUSSION}

The foregoing preliminary results indicate:

1. The ST fusion core, when applied to drive a He-cooled, actinide-bearing molten-salt blanket of moderate power density for producing electric power, incurs moderate plasma physics and device engineering requirements in comparison with those required for maximizing the economic potential of standard tokamak and ST fusion power plants.

2. These requirements compare favorably with the present broad accomplishments of tokamak fusion research in many areas, such as plasma confinement, stability, heat fluxes, auxiliary drive power, and ignition margin (e.g., $T_{\mathrm{i}} n_{\mathrm{DT}} \tau_{\mathrm{E}}$ ), etc. As a result, a large reduction in the size of the fusion core is obtained.

3. The presence of thick MHD instability driven SOL, which is diverted from the inboard limiter, has the potential for ensuring moderate heat fluxes on plasma facing tiles in future ST fusion cores.

4. The use of a single-turn, demountable, unshielded center leg of the TFC introduces qualitatively transforming improvements relating to complexity, technology requirements, reliability, access, and maintainability of the fusion core. These advantages can be exploited to maximize the economic potential of the ST, for fusion as well as for waste transmutation.

5. If the relatively moderate plasma performance is achieved in future steady-state ST fusion cores, and that the He-cooled, actinide-bearing, molten-salt blankets perform as calculated, the ST transmutation of nuclear wastes possesses the highest economic potential among all tokamak fusion power applications.

Several important issues concerning the ST transmutation of actinide wastes are identified below:

1. There is confidence that the high temperature collisionless plasma properties identified in this paper can be produced in ST for long pulses, because the ST plasma has been observed [16] so far to be better than "tokamak-like." However, physics tests at the MA-level in H-D-fueled plasmas [36,37] are indispensable for verification as well as exploration before estimates for future D-T-fueled fusion core can be reliable.

2. Tests of Physics, engineering, and technology (including blanket modules for transmutation) in D-T-fueled ST fusion cores that provide significant $W_{\mathrm{L}}\left(\sim 1 \mathrm{MW} \cdot \mathrm{m}^{-2}\right)$ for long plasma durations should follow the MA tests. The capabilities and operation conditions of the ST core appropriate for future fusion applications can be determined through these tests. ST fusion cores with $R_{0} \leq$ $0.9 \mathrm{~m}$ and $I_{\mathrm{p}} \sim 10 \mathrm{MA}$ are estimated [38] to suffice.

3. Success of the demountable, water-cooled, copper, single-turn center leg for the TFC is central in future ST fusion applications. Its properties under intense $14-\mathrm{MeV}$ neutron irradiation will determine the ultimate viability of the ST approach to magnetic fusion.

4. The alternate concept of molten-salt blanket cooled by liquid metal can in principle handle higher power density than the He-cooled option. This could fit a more compact ST fusion core and may deserve attention in 
view of the high power density capabilities projected for the ST plasma $[27,11]$.

The ST fusion core holds promise in a nearer-term application to help destroy the world's store of long-life actinides. For a longer term, it has the potential of helping to eliminate most actinides on the sites of PWR power plants, leaving mostly shorter-life non-fissile fission wastes for long-term storage. Successful application of the ST fusion core to these energy and environmental needs contributes directly to developing the long-term application of fusion-only power that promises the highest level of environmental compatibility.

\section{ACKNOWLEDGMENT}

The authors wish to thank Drs. D.-K. Sze and I. Sviatoslavsky for valuable discussion during much of this work, Mr. Dennis Strickler for providing the plasma MHD equilibrium shown in Fig. 1, Mr. Paul Fogarty for assistance in developing the configuration concept shown in Fig. 3., and Dr. Robert Krakowski for useful comments on transmutation issues.

\section{REFERENCES}

[1] C. D. Bowman et al., "Nuclear energy generation and waste transmutation using accelerator-driven intense thermal neutron source," Nucl. Instr. and Methods, vol. A230. p. 336, 1992.

[2] "Fusion driven actinide burner design study," EPRI Report ER451, 1977.

[3] T. A. Parish and J. W. Davidson, "Reduction in the toxicity of fission product wastes through transmutation with deuteriumtritium fission reactors," Nucl. Techn., vol. 47, p. 324, 1980.

[4] J. A. Rawlings et al., "CURE: clean use of reactor energy," Westinghouse Hanford Company Report WHC-EP-0268, 1990.

[5] E. T. Cheng, et al., "Actinide transmutation with small tokamak fusion reactors," Int. Conf. Evaluation of Emerging Nuclear Fuel Cycle Systems, Versailles, France, Sept. 11-14, 1995.

[6] E. T. Cheng, "Transmutation of nuclear waste in fusion reactors," Proc. Int. Conf. on Future Nuclear Systems: Emerging Fuel Cycles and Waste Disposal Options, Seattle, Washington, vol. 2, p. 1243, September 12-17, 1993.

[7] Y.-K. M. Peng and E. T. Cheng, "Magnetic fusion driven transmutation of nuclear waste (FTW)," J. Fusion Energy, vol. 12, p. 381, 1993.

[8] Y.-K. M. Peng et al., "Small tokamaks for fusion technology testing," Fusion Techn., vol. 21, p. 1729. 1992.

[9] T. C. Hender et al., "Long term applications of high b spherical tokamaks," Proc. of 22nd EPS Conf. on Controlled Fusion and Plasma Phys, Bournemouth, 1995.

[10] Y-K. M. Peng and D. J. Strickler, "Features of spherical torus plasmas," Nucl. Fusion, vol. 26, p. 769, 1986.

[11] Y.-K. M. Peng, "Prospects and status of low-aspect-ratio tokamaks," Trans. Fusion Techn., vol. 27, 138, 1995.

[12] JET Team, "Fusion energy output in joint European torus," Nucl. Fusion, vol. 32, p. 187, 1992.

[13] JET Team, "Experiments using deuterium-tritium plasmas in the JET tokamak," Plasma Phys. Controlled Nuclear Fusion Research 1992, vol. 1, p. 99, IAEA, 1993.

[14] K. H. Burrell et al., Controlled Fusion and Plasma Heating, p. 271, European Physics Society, 1990.
[15] T. S. Taylor et al., Plasma Phys. and Controlled Nuclear Fusion Research 1992, vol. 1, p. 167, IAEA, 1993.

[16] A Sykes, "Behavior of low-aspect-ratio tokamak plasmas," Plasma Phys. Controlled Fusion, vol. 34, p. 1925, 1992; R. J. Colchin et al., "The small tight aspect ratio tokamak experiment," Phys. Fluids, vol. B5, p. 2481, 1993; A. Sykes et al., Plasma Phys. Controlled Fusion, vol. 35, p. 1051, 1993; A. Sykes et al., "The START spherical tokamak," this symposium.

[17] J. Menard et al., private communications.

[18] F. Troyon et al., "MHD limits to plasma confinement," Plasma Phys. Controlled Fusion, vol. 26, p. 209, 1984.

[19] P. N. Yushmanov et al., "Scaling for tokamak energy confinement," Nucl. Fusion, vol. 30, p. 1999, 1990.

[20] JET Team, "Non-inductive current drive in JET," Plasma Phys. and Controlled Nuclear Fusion Research 1992, vol. 1, p. 587, IAEA, 1993.

[21] H. P. L. de Esch et al., presented at 5th Int. Toki Conf. on Plasma Heating and Current Drive, Toki, Japan, November 1993.

[22] Y. Ohara et al., presented at 5th Int. Toki Conf. on Plasma Heating and Current Drive, Toki, Japan, November 1993.

[23] F. Jobes et al., "Formation of a 100-kA tokamak discharge in the Princeton Large Tokamak," Phys. Rev. Lett., vol. 52, p. $1005,1984$.

[24] D. Moreau et al., Plasma Phys. and Controlled Nuclear Fusion Research 1992, vol. 1, p. 649, IAEA, 1993.

[25] B. A. Nelson et al., "Formation and sustainment of a $150 \mathrm{kA}$ tokamak by coaxial helicity injection," Phys. Rev. Lett. vol. 72, p. $3666,1994$.

[26] K. Erents et al, Proc. of 21st EPS Conf. on Controlled Fusion and Plasma Phys., Montpellier, 1994.

[27] Y.-K. M. Peng et al., to appear in Plasma Phys. and Controlled Nuclear Fusion Research 1994, IAEA, 1995.

[28] A. Sykes et al, "Studies of X-point plasmas in the START tokamak," Proc. of 22nd EPS Conf. on Controlled Fusion and Plasma Phys, Bournemouth 1995.

[29] R. A. Jong et al, "DIII-D edge physics data base," J. Nucl. Materials, vol. 196-198, p. 800, 1992.

[30] Y. M. Peng and J. B. Hicks, "Engineering feasibility of tight aspect ratio tokamak (spherical torus) reactors," Fusion Techn., 1990 , vol. 2, p. 1287, 1991.

[31] N. P. Taylor, "Neutronics study of a spherical tokamak for component testing," this symposium.

[32] J. D. Galambos et al., "Minimum size $Q=1$ and ignited spherical tokamak devices," presented at 11th Topical Mtg. on the Techn. of Fusion Energy, June 20-24, 1994.

[33] S. W. Haney et al., "A SUPERCODE for systems analysis of tokamak experiments and reactors," Fusion Techn., vol. 21, p. $1749,1992$.

[34] R. D. ODell et al,, "Revised users manual for TWODANT: a code package for two-dimensional accelerated neutral particle transport" LA-10049M, Rev. 1, 1984

[35] R. L. Goldston et al., "Advanced tokamak physics - status and prospects," to appear in Controlled Fusion and Plasma Phys., 1995.

[36] A. Drake et al., "The mega-amp spherical tokamak," this symposium.

[37] J. H. Chrzanowski et al., "Engineering overview of the National Spherical Tokamak Experiment," this symposium.

[38] Y.-K. M. Peng, "Spherical tokamak fusion core for testing ignition and technology," presented at the Fusion Power Associates Annual Meeting, Montreal, Canada, 7-8 September 1995; to be submitted to J. Fusion Energy. 


\section{DISCLAIMER}

This report was prepared as an account of work sponsored by an agency of the United States Government. Neither the United States Government nor any agency thereof, nor any of their employees, makes any warranty, express or implied, or assumes any legal liability or responsibility for the accuracy, completeness, or usefulness of any information, apparatus, product, or process disclosed, or represents that its use would not infringe privately owned rights. Reference herein to any specific commercial product, process, or service by trade name, trademark, manufacturer, or otherwise does not necessarily constitute or imply its endorsement, recommendation, or favoring by the United States Government or any agency thereof. The views and opinions of authors expressed herein do not necessarily state or reflect those of the United States Government or any agency thereof. 